\title{
Absence of Renal Phenotype in HEREDITARY HAEMORRHAGIC
}

\section{TELANGIECTASIA}

Lachlan Healy, ${ }^{1,4}$ Kathy Nicholls, ${ }^{2,4}$ Robert Gibson, ${ }^{3,4}$ Damien Stella, ${ }^{3,4}$ Michael Bogwitz, ${ }^{1,4}$ Jessica Taylor, ${ }^{1}$ Maie Walsh, ${ }^{1,4}$ Liz Donaldson, ${ }^{1}$ Ingrid Winship. ${ }^{1,4}$ Departments of Clinical Genetics, ${ }^{1}$ Nephrology, ${ }^{2}$ and Radiology, ${ }^{3}$ The Royal Melbourne Hospital, and The University of Melbourne, ${ }^{4}$ Parkville, Australia

\author{
Lachlan Healy, Research Student \\ Kathy Nicholls, Nephrologist \\ Robert Gibson, Radiologist \\ Damien Stella, Radiologist \\ Michael Bogwitz, Genetic Counsellor \\ Jessica Taylor, Genetic Counsellor \\ Maie Walsh, Clinical Geneticist \\ Liz Donaldson, Genetics Nurse \\ Ingrid Winship, Professor of Genetics
}

\begin{abstract}
Author Contributions -
Lachlan Healy was integral to the project, providing major contributions to protocol development, ethics submission, patient recruitment and communication, test coordination, data collection and analysis, manuscript writing and submission. Kathy Nicholls contributed to conception of the research question, protocol development, patient informed consent, data analysis and manuscript development. Damien Stella and Robert Gibson developed the radiological protocols and analysed the radiology investigations

Michael Bogwitz, Liz Donaldson and Jessica Taylor assisted in database access and patient recruitment, and provided input into the final manuscript.

Maie Walsh assisted in patient recruitment and consent, and provided input into the final manuscript.

Ingrid Winship, Lachlan Healy's academic supervisor and principal investigator, was integral to protocol development, ethics submission, and patient recruitment, and contributed to data analysis and manuscript preparation.
\end{abstract}

Corresponding Author: Lachlan Healy

Department of Clinical Genetics, Royal Melbourne Hospital, Parkville, 3050

healyl@student.unimelb.edu.au

(03) 93427000

\section{ACKNOWLEDGMENTS}

We are grateful to the HHT patient support group, Matty's Soldiers, and to all our research participants.

This is the author manuscript accepted for publication and has undergone full peer review but has not been through the copyediting, typesetting, pagination and proofreading process, which may lead to differences between this version and the Version of Record. Please cite this article as doi: $10.1111 / \mathrm{imj} .14059$

This article is protected by copyright. All rights reserved. 
Abstract Word Count: 78

Main Text Word Count: 1,396

\begin{abstract}
Hereditary Haemorrhagic Telangiectasia is characterised by abnormal blood vessel formation, producing telangiectasiae and arteriovenous malformations in multiple organs. Information regarding possible renal involvement in HHT is limited. This study assessed renal structure and function in eleven patients with genetically confirmed diagnosis and known arteriovenous malformations in lung, liver, GI tract or brain. All had significant current or past epistaxis. Despite the vascularity of the kidneys, we found no evidence of renal involvement. This observation warrants further consideration.
\end{abstract}

\title{
KEY WORDS
}

Hereditary Haemorrhagic Telangiectasia, Arteriovenous Malformations

\section{INTRODUCTION}

Hereditary Haemorrhagic Telangiectasia $(\mathrm{HHT})$ is an autosomal dominant genetic disorder characterised pathologically by dysregulated angiogenesis and clinically by mucocutaneous telangiectasia and internal arteriovenous malformations (AVMs). Physiological regulation of angiogenesis by the Transforming Growth Factor- $\beta$ (TGF$\beta$ ) signalling pathway is disrupted, and activity of Vascular Endothelial Growth Factor A (VEGF-A) is increased. ${ }^{1}$ Mutations in one of several genes can produce the clinical phenotype, the most common causative genes being Endoglin (ENG) and Activin receptor-like kinase 1 (ACVRL1), which respectively encode the proteins Endoglin and activin receptor-like kinase 1 (ALK1).

As a highly vascular organ, one would expect the kidney to be affected by HHT. However, information around this is limited and no screening recommendations exist for the kidney in HHT patients. Clinical interventions for the kidney in HHT seem to be 
unnecessary, and no clinical impact has been identified. Limited data has suggested that there may be renal involvement, albeit usually occult. One report, now 50 years ago, cited telangiectasia on the surface of kidneys in HHT patients, but this has not been confirmed or dismissed. ${ }^{2}$ In one series, microscopic haematuria was reported in a significant proportion of HHT patients, suggesting that AVMs may occur in the kidneys. ${ }^{3}$ Significant renal and also bladder bleeding has also been reported. ${ }^{4,5}$ It may be very useful for individual patients to know if they always have blood in the urine, to inform clinical interpretation of future testing during intercurrent illnesses, and as a safety factor in assessing need for future renal biopsy. We therefore assessed the presence of renal involvement in this cohort, using blood and urine testing, MRI and ultrasound imaging.

\section{METHODS}

After approval of the protocol by the Melbourne Health Human Research Ethics Committee, consenting patients were recruited from the cohort of HHT patients attending our established multidisciplinary clinic at the Royal Melbourne Hospital. ${ }^{6}$ Sequential patients were invited to participate if they met inclusion criteria. Eligibility required confirmed genetic diagnosis with a known mutation in the ENG or ACVRL1 genes. Exclusion criteria included pregnancy, and age under 18 years.

Patient files were accessed to record history of clinical extra-nasal involvement, including liver, lung, brain and gastrointestinal AVMs, and any related interventions. 
Each patient provided an early-morning midstream urine specimen for urinalysis, biochemistry [albumin/creatinine ratio, (UACr), and protein/creatinine ratio, (UPCr)] and automated urine sediment analysis (urine erythrocyte and white cell counts), and serum for creatinine (SeCr) assay. The standard CKD-EPI algorithm was used to estimate glomerular filtration rate (eGFR). ${ }^{7}$

Consenting patients also underwent renal MRI and ultrasound examination according to a standardised procedure empirically developed by two senior Royal Melbourne Hospital radiologists, designed to maximise the probability of detecting the presence of any significant fistulae or aneurysms. MRI examination was subject to the standard Royal Melbourne Hospital safety questionnaire to minimise risks. In patients with intravascular coils or stents, source data was checked for MRI compatibility. MRI with Gadolinium-based contrast was followed by ultrasound examination, using high sensitivity colour flow and spectral Doppler in the main renal arteries and veins, and in any areas identified by the preceding MRI. Scans were reported by one of two senior radiologists.

Unless otherwise specified, data are presented as mean \pm SD. Descriptive statistics were used for pre-specified parameters. Statistical analysis used Sigmaplot V11.0. A $p$ value of $<0.05$ was deemed significant. Power calculation for the study utilised the upper limit of published figures for the prevalence of renal AVMs in the general population of $1 \% .^{8,9}$ The calculation estimates a required sample size of 10 to detect 
a difference in the HHT cohort at a power of $80 \%$ at alpha 0.01 , if the prevalence of AVMs is above $20 \%{ }^{10}$

\section{RESULTS}

Of 39 patients approached, 23 expressed initial interest and 16 of these agreed to consider participation. Eleven of these 16 patients ultimately participated, the other 5 citing inconvenience. Demographic data shown in Table 1. One patient declined all imaging citing time commitments, and another was ineligible for MRI due to epicardial pacemaker wires in situ.

Six of the 11 patients had evidence of internal organ involvement on imaging and / or bubble echo, and four had previously undergone an invasive procedure to manage GIT or pulmonary AVMs.

The 11 participants had a mean Epistaxis Severity Score of $5.03 \pm 2.58$ (median 5.25 , range $0-8.19)$, indicating significant disease severity. In only three was the score below 3 at study entry. All patients had a past history of iron deficiency, with or without anaemia, and all had needed iron supplementation in the past, either orally or intravenously. Several patients had previously required transfusions, and three were currently receiving regular intravenous iron infusions, $1 \mathrm{~g}$ every 3 months.

Renal function was normal in all patients, with mean \pm SD SeCr at $70.7 \pm 15.8 \mu \mathrm{mol} / \mathrm{L}$ and eGFR within the normal expected range (CKD-EPI $97.6 \pm 17.1 \mathrm{ml} / \mathrm{min} / 1.73 \mathrm{~m}^{2}$ ). 
No patient had any evidence of abnormal albuminuria or proteinuria. Urinary RBC and WBC were also normal.

MRI and ultrasound examinations did not reveal any signs of renal AVMs. In one patient, a 49-year-old woman with a mutation in the ACVRL1, a small simple cyst was found in each kidney, measuring 9 and $14 \mathrm{~mm}$.

One patient, a 72-year-old man with a mutation in the ACVRL1, had a lesion suggestive of a renal tumour on ultrasound scan. He was immediately withdrawn from the study, and referred for urgent urological assessment and CT staging. He underwent a left radical nephrectomy for papillary renal cell carcinoma, type II, and has made an uneventful recovery.

\section{DISCUSSION}

Genetic mutations in participants in this study were typical of those, both of our larger cohort of HHT patients, and of those reported in the literature. ${ }^{6}$ It is difficult to reconcile the absence of renal involvement in $\mathrm{HHT}$ with the high vascularity of the kidney and the high prevalence of extrarenal internal lesions. We cannot definitively exclude the presence of very small malformations. However, the normal findings in the study are consistent with clinical experience.

Several factors may contribute to exemption of the kidney from the angiogenic effects seen in other organs in HHT. Physiologically, VEGF and other angiogenic factors are counterbalanced by angiostatic factors such as thrombospondin-1 (TSP-1). TSP-1 is 
expressed in the kidney and is inversely correlated with endoglin levels in experimental models of $\mathrm{HHT} .^{11}$ The dysregulated balance between angiogenic and angiostatic factors in $\mathrm{HHT}$ is complex and the precise mechanisms remain unclear. $^{12}$ The VEGF system comprises multiple isoforms, interacting ligands, membranebound and soluble receptors, and modulators of receptor binding. ${ }^{13}$ The renal vasculature has many unique features, and VEGF action may also be locally modulated by multiple molecules including TSP-1 and Notch. The emerging relationship between ALK1 and Notch is an area of active research. Notch is expressed in the kidney and is part of a complex signal transduction pathway that regulates multiple critical physiological processes. The Notch response is modulated at multiple levels, interacting with other signalling networks including the TGF $\beta / B M P$ pathways. ${ }^{14}$ Notch-TGF $\beta$ crosstalk is mechanistically relevant to renal fibrosis, and may critically determine development and remodelling in multiple organs, especially lung and kidney, via interaction of multiple ligands including BMP9/ALK1. ${ }^{15,16}$ However, there is no evidence that HHT patients lacking ALK1 develop kidney problems at a clinical level. It is physiologically feasible that HHT patients are genetically protected from renal fibrosis. Progressive renal disease is characterised by loss of the renal microvasculature, mediated in part by altered local expression of both angiogenic (VEGF) and antiangiogenic factors. ${ }^{17}$

Mutations present in HHT may favour renal cyst formation. ${ }^{18}$ Increased angiogenesis and VEGF expression are reported in the cysts of autosomal dominant polycystic 
kidney disease (ADPKD), suggesting a possible role for VEGF in increasing vascular permeability and promoting cyst formation in this disorder. ${ }^{18}$ Cyst walls in ADPKD contain rich capillary networks and evidence of vascular malformations, with altered expression of VEGF, metalloproteinase and integrin subtypes. However, sporadic renal cysts are common with increasing age, and our small study did not indicate an abnormally high rate of cyst formation. ${ }^{19,20}$ While one patient at age 49 had one cyst in each kidney, these are likely to be incidental. From the fifth to the ninth decade of life, the prevalence of renal cysts in the general population reportedly increases from $5.1 \%$ to $36.1 \%{ }^{20}$ It is likely that the single case of renal cell carcinoma was an incidental finding.

\section{CONCLUSION}

In conclusion, we confirm our prior suspicion of a lack of renal phenotype in HHT. Further investigations into the mechanism for this could be considered. 


\section{REFERENCES}

1. Sadick H, Riedel F, Naim R, Goessler U, Hormann K, Hafner M, Lux A. Patients with hereditary hemorrhagic telangiectasia have increased plasma levels of vascular endothelial growth factor and transforming growth factor-beta1 as well as high ALK1 tissue expression. Haematologica 2005; 90: 818-28.

2. Halpern M, Turner AF, Citron BP. Hereditary hemorrhagic telangiectasia: an angiographic study of abdominal visceral angiodysplasias associated with gastrointestinal hemorrhage. Radiology 1968; 90: 1143-9.

3. Di Gennaro L, Ramunni A, Suppressa P, Guastamacchia E, Resta F, Sabba C. Asymptomatic Microhematuria: An Indication of Hereditary Hemorrhagic Telangiectasia? J Urol 2005; 173: 106-109.

4. Ziani M, Valignat C, Lopez JG, Ruffion A, Plauchu H, Perrin P. Renal arteriovenous malformation requiring surgery in Rendu-Osler-Weber disease (hereditary hemorrhagic telangiectasia). J Urol 2000; 164: 1292-3.

5. Babushkina GD, Davidov MI, Kir'ianova TV. Profuse intravesical hemorrhage caused by Rendu-Osler-Weber disease. Klin Med (Mosk) 2000; 79: 67-8.

6. Salaria M, Taylor J, Bogwitz M, Winship I. Hereditary haemorrhagic telangiectasia, an Australian cohort: clinical and investigative features. Int Med J 2014; 44: 639-44.

7. Levey AS, Bosch JP, Lewis JB, Greene T, Rogers N, Roth D. A more accurate method to estimate glomerular filtration rate from serum creatinine: a new prediction equation. Ann Intern Med 1999; 130: 461-70.

8. Cho KJ, Stanley JC. Non-neoplastic congenital and acquired renal arteriovenous malformations and fistulas. Radiology 1978; 129: 333-43.

9. Cura M, Elmerhi F, Suri R, Bugnone A, Dalsaso T. Vascular malformations and 
arteriovenous fistulas of the kidney. Acta Radiol 2010; 51: 144-149.

10. Kane SP. Sample Size calculator. Clincalc:

http://clincalc.com/stats/samplesize.aspx Updated July 1, 2017. Accessed April 12, 2018.

11. Ardelean DS, Letarte M. Anti-angiogenic therapeutic strategies in hereditary hemorrhagic telangiectasia. Front Genet 2015; 6.

12. Garrido-Martin EM, Nguyen HL, Cunningham TA, Choe SW, Jiang Z, Arthur HM, Lee YJ, Oh SP. Common and distinctive pathogenetic features of arteriovenous malformations in hereditary hemorrhagic telangiectasia 1 and hereditary hemorrhagic telangiectasia 2 animal models. Arterioscler Thromb Vasc Biol 2014; 114.

13. Ostendorf T, De Vriese AS, Floege J. Renal side effects of anti-VEGF therapy in man: a new test system. Nephrol Dial Transplant 2007; 22: 2778-80.

14. Borggrefe T, Lauth M, Zwijsen A, Huylebroeck D, Oswald F, Giaimo BD. The Notch intracellular domain integrates signals from Wnt, Hedgehog, TGFbeta/BMP and hypoxia pathways. Biochim Biophys Acta. 2016; 1863: 303-13.

15. Xiao Z, Zhang J, Peng X, Dong Y, Jia L, Li H, Du J. The Notch Y-secretase inhibitor ameliorates kidney fibrosis via inhibition of TGF- $\beta / S m a d 2 / 3$ signalling pathway activation. Int J Biochem Cell Biol 2014; 55: 65-71.

16. Aspalter IM, Gordon E, Dubrac A, Ragab A, Narloch J, Vizan P, et al. Alk1 and Alk5 inhibition by Nrp1 controls vascular sprouting downstream of Notch. Nat Commun. 2015; 6: 7264.

17. Kang DH, Kanellis J, Hugo C, Truong L, Anderson S, Kerjaschki D, et al. Role of the microvascular endothelium in progressive renal disease. J Am Soc Nephrol. 2002; 13: 806-16. 
18. Bello-Reuss E, Holubec K, Rajaraman S. Angiogenesis in autosomal-dominant polycystic kidney disease. Kidney Int. 2001; 60: 37-45.

19. Tada S, Yamagishi J, Kobayashi H, Hata Y, Kobari T. The incidence of simple renal cyst by computed tomography. Clin Radiol. 1983; 34: 437-9.

20. Terada N, Ichioka K, Matsuta Y, Okubo K, Yoshimura K, Arai Y. The natural history of simple renal cysts. J Urol. 2002; 167: 21-3. 
Table 1. Patient demographic data

\begin{tabular}{|lc|}
\hline \multicolumn{1}{|l|}{$\begin{array}{c}\text { Males } \\
\text { Females }\end{array}$} & 11 \\
\hline & 6 \\
\hline Age (mean \pm SD years) & $43 \pm 14.1$ \\
\hline Patients with ACVRL1 Mutation & 7 \\
\hline Patients with ENG Mutation & 4 \\
\hline Patients with evidence of internal organ involvement & 6 \\
\hline Patients undergoing renal function testing & 11 \\
\hline Patients also undergoing ultrasound and MRI & 9 \\
\hline Patients also undergoing ultrasound without MRI & 1 \\
\hline
\end{tabular}

This article is protected by copyright. All rights reserved. 


\section{Absence of Renal Phenotype in HEREDITARY HAEMORRHAGIC}

\section{TELANGIECTASIA}

Lachlan Healy, ${ }^{1,4}$ Kathy Nicholls, ${ }^{2,4}$ Robert Gibson, ${ }^{3,4}$ Damien Stella,, ${ }^{3,4}$ Michael Bogwitz, ${ }^{1,4}$ Jessica Taylor, ${ }^{1}$ Maie Walsh, ${ }^{1,4}$ Liz Donaldson, ${ }^{1}$ Ingrid Winship. ${ }^{1,4}$ Departments of Clinical Genetics, ${ }^{1}$ Nephrology, ${ }^{2}$ and Radiology, ${ }^{3}$ The Royal Melbourne Hospital, and The University of Melbourne, ${ }^{4}$ Parkville, Australia

Lachlan Healy, Research Student

Kathy Nicholls, Nephrologist

Robert Gibson, Radiologist

Damien Stella, Radiologist

Michael Bogwitz, Genetic Counsellor

Jessica Taylor, Genetic Counsellor

Maie Walsh, Clinical Geneticist

Liz Donaldson, Genetics Nurse

Ingrid Winship, Professor of Genetics

\section{Author Contributions -}

Lachlan Healy was integral to the project, providing major contributions to protocol development, ethics submission, patient recruitment and communication, test coordination, data collection and analysis, manuscript writing and submission. Kathy Nicholls contributed to conception of the research question, protocol development, patient informed consent, data analysis and manuscript development. Damien Stella and Robert Gibson developed the radiological protocols and analysed the radiology investigations

Michael Bogwitz, Liz Donaldson and Jessica Taylor assisted in database access and patient recruitment, and provided input into the final manuscript.

Maie Walsh assisted in patient recruitment and consent, and provided input into the final manuscript.

Ingrid Winship, Lachlan Healy's academic supervisor and principal investigator, was integral to protocol development, ethics submission, and patient recruitment, and contributed to data analysis and manuscript preparation.

Corresponding Author: Lachlan Healy

Department of Clinical Genetics, Royal Melbourne Hospital, Parkville, 3050

healyl@student.unimelb.edu.au

(03) 93427000

\section{ACKNOWLEDGMENTS}

We are grateful to the HHT patient support group, Matty's Soldiers, and to all our research participants.

Abstract Word Count: 78

Main Text Word Count: 1,396 


\begin{abstract}
Hereditary Haemorrhagic Telangiectasia is characterised by abnormal blood vessel formation, producing telangiectasiae and arteriovenous malformations in multiple organs. Information regarding possible renal involvement in HHT is limited. This study assessed renal structure and function in eleven patients with genetically confirmed diagnosis and known arteriovenous malformations in lung, liver, GI tract or brain. All had significant current or past epistaxis. Despite the vascularity of the kidneys, we found no evidence of renal involvement. This observation warrants further consideration.
\end{abstract}

\title{
KEY WORDS
}

Hereditary Haemorrhagic Telangiectasia, Arteriovenous Malformations 


\section{University Library}

\section{- M M N E R VA A gateway to Melbourne's research publications}

Minerva Access is the Institutional Repository of The University of Melbourne

\section{Author/s:}

Healy, L;Nicholls, K;Gibson, R;Stella, D;Bogwitz, M;Taylor, J;Walsh, M;Donaldson, L;Winship, ।

Title:

Absence of renal phenotype in hereditary haemorrhagic telangiectasia

Date:

2018-10-01

\section{Citation:}

Healy, L., Nicholls, K., Gibson, R., Stella, D., Bogwitz, M., Taylor, J., Walsh, M., Donaldson, L. \& Winship, I. (2018). Absence of renal phenotype in hereditary haemorrhagic telangiectasia. INTERNAL MEDICINE JOURNAL, 48 (10), pp.1255-1257. https://doi.org/10.1111/imj.14059.

Persistent Link:

http://hdl.handle.net/11343/284586 